\title{
Optimization of Parameters for MRR in Drilling Operation using Jaya Algorithm
}

\author{
Sudesh Garg, Prem Singh, Md. Suhaib Ansari
}

Department of Mechanical Engineering, Swami Keshvanand Institute of Technology, Management \& Gramothan, Jaipur-302017 (INDIA)

Email: sudesh.garg@skit.ac.in; prem.singh@skit.ac.in; suhaib.ansari @ skit.ac.in Received 6.09.2021, received in revised form 17.09.2021, accepted 17.09.2021 doi: $10.47904 / I J S K I T .11 .2 .2021 .63-65$

\begin{abstract}
Drilling is the process in which material is removed by the help of curved drills. Wide varieties of drill processes are available to serve different purposes with maximize the rate of material removal.This paper describes optimization statement for maximization of MRR with suitable constraints. The formulated optimization problem is solved using Jaya Algorithm.The obtained results are compared with literature.
\end{abstract}

Keywords- MRR, Drilling, Jaya Algorithm.

\section{INTRODUCTION}

Various cutting tools are available for drilling. Drilling is used to create holes with the help of curved drills which are multi-point cutting tools. Wide varieties of drill processes are available to serve different purposes with maximize the rate of material removal. The rate of material removal can be maximized using optimum parameters i.e. speed of spindle, cutting depth of drill hole, and feed rate.

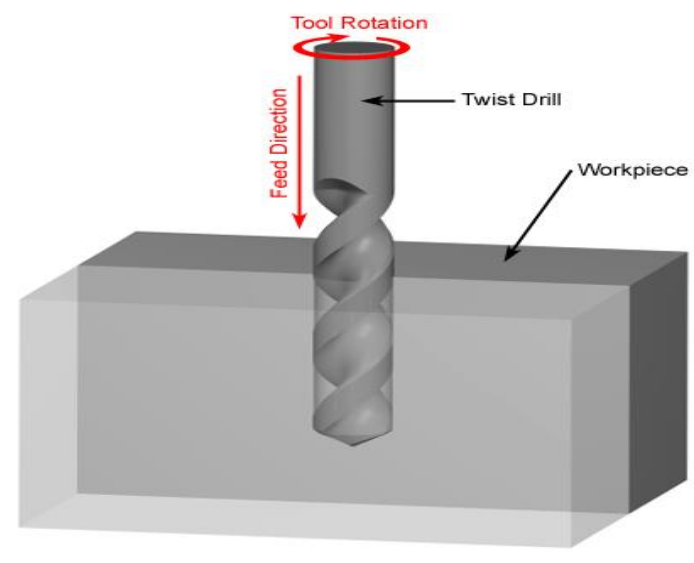

Fig. 1 Drilling Process

Recently, different optimization methods have been applied to optimize the parameters for MRR, such as Kumar Suresh et al. [1] depicted the optimal values of drilling parameters in their experimental study. They basically developed empirical model and used the Fire Fly Algorithm (FFA) for getting the best fit values of the parameters of drilling for the titanium alloy.

Jeet et al. [2] used the Genetic algorithm and simulated annealing (SA) for calculating the optimal values for the parameters feed rate, drill angle, and rotational speed along with the forecasted fitness values.

Mohan et al. [3] applied the Genetic algorithm (GA) for getting optimum MRR (material removal rate) concern with the better finish of the surface. He suggested that diameter of hole and the rotation speed had major effect on Material Removal Rate.

B. Latha et al. [4] conducted an experiment on CNC for investigating the effect of machining parameters on the drilled hole.They developed regression model of second order and optimize the drilling condition by using the NSGA-II teqhnique.

Lip HuatSaw et al.[5] conducted an experiment for investigating the effect of machining parameters on drill wear used Adaptive Neuro Fuzzy Inference system and getting the best fit values of the parameters of drilling using genetic algorithm.

In this ongoing study the Computer numerical control (CNC) machine namely, CNC MILL MT-250 specification of machine is represented in Table 1. Materials of machine tool and work piece are chosen as K-series, tungsten carbide HS drill (K-40) and AISI H-11 die steel material work piece $(150 \mathrm{~mm} \mathrm{x}$ $60 \mathrm{~mm} \times 30 \mathrm{~mm}$ ), respectively for experimention.

Table 1 Specification of Machine

\begin{tabular}{|c|c|}
\hline Specifications & Unit \\
\hline Model No. & MT 250 \\
\hline Spindle speed (Max) & 4000 RPM \\
\hline $\mathrm{x}$ & $250 \mathrm{~mm}$ \\
\hline $\mathrm{y}$ & $160 \mathrm{~mm}$ \\
\hline $\mathrm{z}$ & $200 \mathrm{~mm}$ \\
\hline Table size $\left(\mathrm{L}^{*} \mathrm{~W}\right)$ & $1150 \mathrm{~mm} * 1150 \mathrm{~mm}$ \\
\hline Rapid rate & $700 \mathrm{~mm} / \mathrm{min}$ \\
\hline
\end{tabular}

\section{OPTIMIZATION MODEL}

This section explains the optimization statement for material removal rate in drilling operation. The main purpose of drilling is to maximize material removal rate (MRR). Therefore, an optimization problem is stated to maximize material removal rate with appropriate constraints.

Table 2 Comparison of optimum parameters for MRR

\begin{tabular}{|c|c|c|}
\hline $\begin{array}{c}\text { Design } \\
\text { Variables/MRR }\end{array}$ & $\begin{array}{c}\text { Optimum } \\
\text { Values [6] }\end{array}$ & $\begin{array}{c}\text { Optimum Values } \\
\text { (Jaya-Algorithm) }\end{array}$ \\
\hline $\mathrm{N}(\mathrm{RPM})$ & 1200 & 1200 \\
\hline $\mathrm{F}(\mathrm{mm} / \mathrm{rev})$ & 0.02 & 0.02 \\
\hline $\mathrm{d}(\mathrm{mm})$ & 10 & 10.02 \\
\hline MRR & $\mathbf{1 4 7 5}$ & $\mathbf{1 4 8 7}$ \\
\hline
\end{tabular}


The speed of spindle $(\mathrm{N})$, depth cut of drill hole (d), and feed rate (f) are considered as design variables. These are stated in vector form

$$
\mathrm{x}=\left[\begin{array}{lll}
\mathrm{N} & \mathrm{d} & \mathrm{f}
\end{array}\right]^{\mathrm{T}}
$$

Now, optimization problem is described for MRR, its expression is obtained using RSM technique in ANOVA [6] for design variables as

Minimize $Z=-$ Maximize $(M R R)$

$=-(-342.1+0.6509 N+15.1 d+32873 f$

$-0.000026 N^{2}+1210909 f^{2}-0.449 d^{2}$

$-5.62 N \times f+0.00175 N \times d$

$-240 d$

$\times f$ )

Bound constraints for design variables are given as

$$
x_{L_{i}} \leq x_{i} \leq x_{U_{i}} \text { for } i=1 \text { to } 3
$$

Where $\mathrm{x}_{\mathrm{L}_{\mathrm{i}}}$ and $\mathrm{x}_{\mathrm{U}_{\mathrm{i}}}$ define the lower and upper boundsfor the $\mathrm{x}_{\mathrm{i}}$ design variable.

\section{OPTIMIZATION TECHNIQUE}

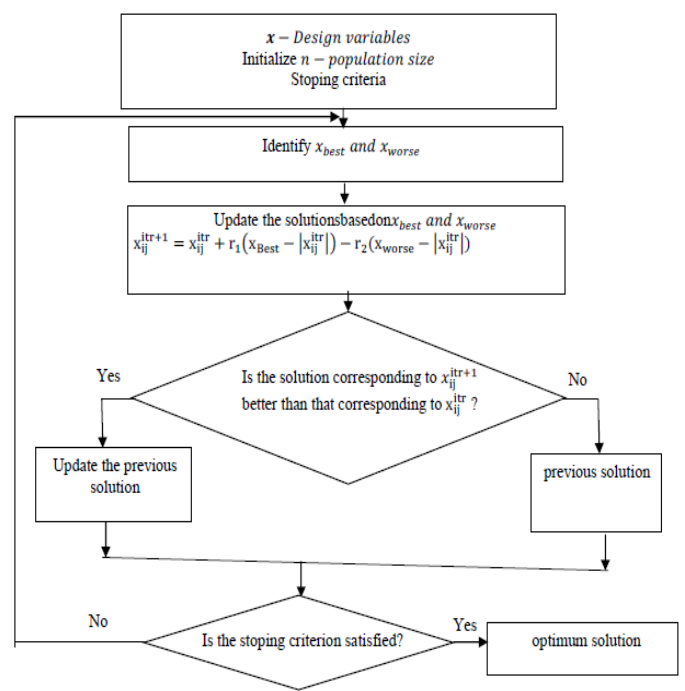

Fig. 2 An optimization procedure of Jaya Algorithm

Conventional algorithms and algorithmsbased on nature can be applied to the formulated optimization problem stated in previous section. Conventional algorithms give a local optimum solution due to converge of optimum solution near to initial point [7].

It takes more compujtation time by calculating gradient of objective function.Algorithms based nature like GA, PSO, and Ant colony optimization algorithm use control parameters for their converging. However, other nature-based algorithm as teaching-earning-based optimization algorithm does not require any specific control parameters.

Generally, two phases (teacher phase and the learner phase) are associated with this algorithm [8]. Moreover, Jaya algorithm is also nature-based algorithm. One phase is associated with this algorithm, andcomparatively it issimple and easier to understand $[9,10]$. A description of Jaya algorithm is presented in Fig. 2

\section{RESULTS \& DISCUSSIONS}

In this section, the formulated problem with maximization of MRR is solved using Jaya algorithm. The values of upper and lower bounds are taken as

$$
\begin{gathered}
400 \leq N \leq 1200(R P M) \\
10 \leq d \leq 20 \mathrm{~mm} \\
0.01 \leq f \leq 0.02 \frac{\mathrm{mm}}{\mathrm{rev}}
\end{gathered}
$$

This algorithm is coded in MATLAB. In order to find the best value of MRR and optimum design variables, 10 numbers of runs, 10 number of populations and 100 iterations are selected for this algorithm. The rate of convergence for best MRR values is shown in Fig.3 It takes about 0.30 seconds for its convergence. The optimum results are compared with Table 3, S.No. 10, page no. 404 [6]. The optimum results are shown in Table 2. It shows that computations efficiency and convergence rate is better compared to optimization algorithms.

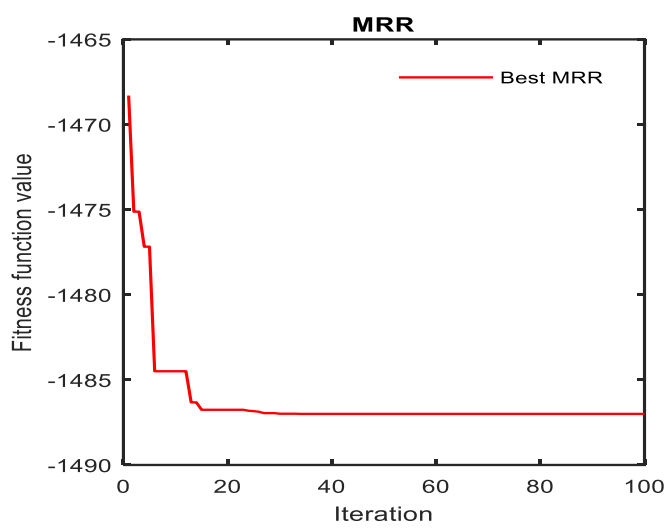

Fig. 3 Convergence Rate for best MRR

\section{CONCLUSIONS}

This paper describes optimization statement for maximization of MRR with suitable constraints. The formulated optimization problem is solved using Jaya Algorithm. Optimum results obtained using this algorithm is compared with the reference paper [6]. These results show that computations efficiency and convergence rate is better compared to other optimization algorithms.

\section{REFERENCES}

[1] Kumar B. Suresh, Vijayan V., Baskar N,"Optimization of Drilling Process Parameters for Material Removal Rate and Surface Roughness on Titanium Alloy using Response Surface Methodology and Fire Fly Algorithm", Asian Journal of Research in Social Sciences and Humanities, Vol. 6, Issue-5,pp 1251-1267,2016.

[2] Jeet S., Barua A., Bagal D.K,"Multi-Parametric Optimization during Drilling of Aerospace Alloy (UNS A97068) Using Hybrid RSM-GRA, GA and SA," International Journal of Management, Technology And Engineering,vol. 9, no. 2, pp. 2501-2509, 2019.

[3] Mohan NS. "Optimization of Process Parameters of Drilling 
in Ti-Tib Composites using Taguchi Technique," IRD India, vol. 2, no. 4, pp. 1-5, 2016.

[4] B. Latha; V.S. Senthil kumar, "Simulation Optimization of Process Parameters in Composite Drilling Process Using Multi-objective Evolutionary Algorithm," International Conference on Advances in Recent Technologies in Communication and Computing(IEEE), 2009

[5] Lip. Saw; Wen Ho "Sensitivity analysis of drill wear and optimization using Adaptive Neuro fuzzy -genetic algorithm technique toward sustainable machining," vol. 20, no. 4, pp. 3289-3298, 2018.

[6] Garg. S., Goyal. Ravi, "Effect of Material Removal Rate (MRR) on AISI H11 Die Steel in Drilling using Face Centered Design," IJSTE-International Journal of Science Technology \& Engineering, vol. 1 , no. 12 , pp. 400-410, 2015

[7] Lip. Saw; Wen Ho "Sensitivity analysis of drill wear and optimization using Adaptive Neuro fuzzy -genetic algorithm technique toward sustainable machining," vol. 20, no. 4, pp. 3289-3298, 2018

[8] J.S. Arora: Introduction to Optimum Design, third ed., Reed Elsevier India Private Limited, India (2012).

[9] [9] Rao R.V., Teaching Learning Based Optimization algorithm: and its Engineering Applications, Springer (2015).

[10] R.V. Rao, Jaya : A simple and new optimization algorithm for solving constrained and unconstrained optimization problems, International Journal of Industrial Engineering Computations, 7(1), 19-34 (2016). 